Onkologe 2020 $\cdot 26: 976$

https://doi.org/10.1007/s00761-020-00814-6

(c) Springer Medizin Verlag GmbH, ein Teil von Springer Nature 2020

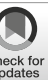

Klaus Höffken

Berlin, Deutschland

\title{
Peer-Review als zentrales Qualitätsmerkmal in der wissenschaftlichen Publikationslandschaft
}

\section{Kommentar zum Leserbrief}

Ullrich G (2020) Personalbedarf in der Psychoonkologie. Onkologe. https://doi.org/10. 1007/s00761-020-00809-3

\section{Originalpublikation \\ Mehnert-Theuerkauf A, Faller $\mathrm{H}$, Herschbach P et al (2020) Psychoonkologischer Versor- gungsbedarf in Krebszentren. Onkologe 26: 178-184. https://doi.org/10.1007/s00761- 019-00689-2}

Herausgeber und Verlag begrüßen nachdrücklich eine wissenschaftliche Diskussion zu Beiträgen der Zeitschrift - auch strittige Diskussionen und die Darlegung unterschiedlicher Ansichten.

Im vorliegenden Schriftwechsel zwischen Frau Prof. A. Mehnert-Theuerkauf und Herrn Dr. G. Ullrich muss auf Folgendes hingewiesen werden:

Der Beitrag von Mehnert-Theuerkauf und Mitautoren wurde von zwei Fachexperten begutachtet (sog. Peer-Review) und nach entsprechenden Hinweisen der Gutachter überarbeitet und anschließend von den Herausgebern zur Veröffentlichung freigegeben.

Der Leserbrief von Ullrich verweist auf eigene Publikationen auf einem sog. "preprint server“ (figshare). Diese Form der Veröffentlichungen findet zunehmend Gebrauch, da so die Ergebnisse ohne den Zeitverzug des Peer-Reviews veröffentlicht werden können. Allerdings muss beachtet werden, dass diese Veröffentlichungen - wie die beiden
Selbstzitate von Dr. Ullrich - unbegutachtet sind. Ferner sind Form und Charakter der dort veröffentlichten 27seitigen Kritik an dem Beitrag von Mehnert et al. kritikwürdig.

Dennoch haben sich Herausgeber und Verlag entschieden, nach dem Prinzip der guten wissenschaftlichen Praxis und der Transparenz den Leserbrief von Dr. Ullrich zu veröffentlichen.

Prof. Dr. Klaus Höffken

Federführender Herausgeber

\section{Korrespondenzadresse}

\section{Prof. Dr. Klaus Höffken}

Welserstraße 21, 10777 Berlin, Deutschland Hoeffken.Editor@med.uni-duesseldorf.de

Interessenkonflikt. K. Höffken gibt an, dass kein Interessenkonflikt besteht. 